\title{
Reproductive Strategy of Podisus nigrispinus Females under Different Feeding Intervals
}

\author{
F.S. Ramalho, ${ }^{1, *}$ J. Mezzomo, ${ }^{1}$ W.P. Lemos,${ }^{1}$ C.M. Bandeira, ${ }^{1}$ \\ J.B. Malaquia, ${ }^{1}$ J.P.S. Silva, ${ }^{1}$ G.L.D. Leite ${ }^{2}$ and J.C. Zanuncio ${ }^{3}$
}

\begin{abstract}
An attempt was made to quantify the influence of prey scarcity on longevity and on the reproductive variables of females of the predator Podisus nigrispinus (Dallas) (Heteroptera: Pentatomidae). The predators received prey (Alabama argillacea) of different sizes, viz., 50 $\mathrm{mg}$ (small prey) or $220 \mathrm{mg}$ (large prey), for a period of $24 \mathrm{~h}$, daily or every 2, 4, 8 or 16 days. In an additional trial, the predators were provided only with water or kept without food, in which latter condition they lived a significantly shorter time. Individuals that received large prey in excess (every day) and at 16-day intervals lived significantly less, while the longevity of those that fed on small prey did not differ significantly between feeding intervals. Predators that fed less frequently laid fewer eggs, with increased intervals between clutches. The results were more marked in females fed on small prey; however, evidence of trade-off between reproduction and survival was detected only in predators that received large prey. The results suggest a type of trade-off, where longevity is maintained at the expense of reproduction. This strategy can contribute to the establishment and survival of $P$. nigrispinus in an environment of fluctuating food supply.
\end{abstract}

KEY WORDS: Predators; food scarcity; life history; biological control.

\section{INTRODUCTION}

The representatives of the genus Podisus are generalist predators, which have been found in many parts of the American continent, feeding mainly on immature lepidopterans and coleopterans $(7,8)$. In the cotton agroecosystem the species Podisus nigrispinus (Dallas) (Heteroptera: Pentatomidae) has been able to kill, efficiently, the major defoliating pest in Brazil, the cotton leafworm (Alabama argillacea Hübner) (18).

Alimentary limitation affects several parameters in the life history of arthropods, such as development rate (25), body size (14,21), survival (35), fecundity $(14,25)$ and diapause (1). Besides, food scarcity may promote limited growth in the population (9) or increase inter-species competition $(19,35)$. However, there is no unanimity among the researchers about the possibility of food scarcity for predators being a common phenomenon in nature. According to some researchers, the intensity of natural alimentary limitation may vary in time and/or space $(25,36)$ and, in some cases, predators are not subjected to it $(4,13)$.

An important attribute of predators, as agents for biological control, is their ability to establish populations and to persist in a specific ecosystem. Consequently, efficient

\footnotetext{
Received March 15, 2007; accepted Sept. 16, 2007; http://www.phytoparasitica.org posting Dec. 11, 2007.

${ }^{1}$ Unidade de Controle Biológico (UCB)/Embrapa Algodão, 58107-720, Campina Grande, State of Paraiba, Brazil. *Corresponding author [e-mail: framalho@pesquisador.cnpq.br].

${ }^{2}$ UFMG/Núcleo de Ciência agrárias, Montes Claros, State of Minas Gerais, Brazil [e-mail: gldleite@ufmg.br].

${ }^{3}$ Depto. de Biologia Animal, Universidade Federal de Viçosa, 36571-000, Viçosa, State of Minas Gerais, Brazil [e-mail: zanuncio@ufv.br].
} 
predators present adaptations to drastic changes in prey density, allowing them to survive and reproduce even during periods of prey scarcity. Such adaptations are reflected in the life-history characteristics of the predator (7). Predators that are frequently found in agricultural habitats possess physiological and/or behavioral attributes that allow them to maintain populations in these unstable environments $(32,34)$.

The life-history strategy of predators can be seen as an adjustment in the distribution of energy among competing physiological demands that are associated with age, reproductive status and physiological state $(11,27)$. The presence of predators in certain environments and their effect on prey dynamics depends on their ability to find prey, the number and type of prey, and the distribution of energy obtained from the prey among the components of the life history of the predator $(3,17)$.

The energy obtained when predators attack multiple prey is probably enough to satisfy their physiological needs. However, when food becomes scarce, energy should be used initially to maintain the metabolism, growth, development and reproduction being addressed thereafter $(2,12)$. This means that the suppression of reproduction tends to increase survival, allowing predators to resist until they obtain enough energy for the costly reproductive process $(34)$.

In insects, evidence of this process - which is termed 'physiological trade-off' between survival and reproduction - has been found in some coleopterans $(31)$, hemipterans $(15,28)$ and dipterans $(10,26)$. In pentatomids, this process was observed with evidence in Podisus maculiventris Say (17,34), Podisus sagitta (Fab.) (7) and Podisus rostralis (Stål) (23). However, in some orthopteran (6), coleopteran (20) and dipteran (16) species, such evidence was not found.

Understanding predator adaptation to the environment is of great importance for integrated pest management. Food scarcity may be common in nature and it is an important parameter to consider in relation to the efficient use of this predator in biological control programs.

The purpose of the study was to determine the effect of different feeding regimens in relation to prey size and availability, on the reproduction and longevity of females of $P$. nigrispinus, in the laboratory. The results are discussed in relation to the adaptation strategies shown by this predatory bug in times of prey scarcity.

\section{MATERIALS AND METHODS}

The research was conducted at Unidade de Controle Biológico (UCB) - Embrapa Algodão, Campina Grande, Paraíba, Brazil, in growth chambers held at $25^{\circ} \mathrm{C}, 60 \pm 10 \%$ r.h. and a photoperiod of $14: 10 \mathrm{~h}$ (L:D). The specimens of the predator $P$. nigrispinus and of the prey $A$. argillacea used in this study were from colonies of a mass rearing maintained at UCB/Embrapa Algodão. In the P. nigrispinus rearing, Musca domestica and Tenebrio molitor L. larvae were used as alternative prey. Alabama argillacea larvae were fed on cotton leaves of CNPA cv. 'Precoce 2' (Gossypium hirsutum L. race latifolium).

The experimental design was a randomized complete block, with eight replications, each with ten $P$. nigrispinus females. Three experiments were conducted: exp. 1, predator fed with small prey $(50 \pm 10 \mathrm{mg} / \mathrm{larva})$; exp. 2 , with large prey $(220 \pm 10 \mathrm{mg} / \mathrm{larva})$; and exp. 3 , just water (without prey) or no prey or water. In exps. 1 and 2 , the treatments consisted of one $A$. argillacea for each predator, for a period of $24 \mathrm{~h}$, daily or every $2,4,8$ or 16 days, or abundant prey (six large larvae, daily). 
Newly emerged females of $P$. nigrispinus were coupled immediately after eclosion and maintained for 5 days in covered plastic cups of $100 \mathrm{ml}$, where water and $5^{\text {th }}$ instar larvae of $A$. argillacea were supplied. For each treatment, mated $P$. nigrispinus females (max. 5 days old) were collected from the rearing containers and conditioned, individually, in white plastic cups of $100 \mathrm{ml}$. Except in the exp. 3 treatment with no water supply to the predator, a hole was made in the cup cover into which a plastic anesthetic tube of $2.5 \mathrm{ml}$ was inserted containing distilled water. A cotton plug in the open end of the tube avoided water draining away.

Each female was observed daily, and mortality and egg clutches were recorded until the female's death. For each treatment tested, the following parameters were evaluated: preoviposition and oviposition periods, age at the first clutch, number of eggs in the first clutch, number of eggs and clutches per female, number of eggs and of clutches per female per day, clutch interval and longevity of females.

The effects of different feeding intervals on survival and on reproductive variables of the predator $P$. nigrispinus were analyzed, employing PROC GLM procedures (30). Means were compared by the Student-Newman-Keuls test $(P<0.05)$.

\section{RESULTS}

Exp. 1 (large prey) The feeding intervals affected significantly the longevity of $P$. nigrispinus $(\mathrm{F}=4.66 ; \mathrm{df}=5,42 ; P=0.004)$ (Table 1). The predators fed at intervals of 2 , 4 or 8 days had greater longevity than those fed with abundant prey or every 16 days (Table 1) and, additionally, mortality started in at only 20 days of age. The feeding intervals also affected significantly the preoviposition period of $P$. nigrispinus $(\mathrm{F}=3.16 ; \mathrm{df}=5,34$; $P=0.005$ ), which was longer in those predators fed every 8 days in relation to those fed an excess of prey (Table 1).

The number of eggs in the first clutch of $P$. nigrispinus was also influenced by the feeding intervals to which it was subjected $(\mathrm{F}=4.88 ; \mathrm{df}=5,42 ; P=0.004)$, feeding on excessive prey facilitating the deposition of a larger clutch than those found in females fed every 8 or 16 days (Table 1 ). The number of eggs per female per day $(\mathrm{F}=6.52 ; \mathrm{df}=5,42$; $P=0.003)$ and of clutches per female per day $(\mathrm{F}=2.78 ; \mathrm{df}=5,42 ; P=0.008)$ was affected by feeding intervals to which the predators were subjected. The values for both reproductive variables were superior when prey was supplied in excess, daily or every 2 or 4 days (Table 1). The number of eggs per female ( $F=3.70 ; \mathrm{df}=5,42 ; P=0.005)$ and of clutches per female $(\mathrm{F}=2.69 ; \mathrm{df}=5,41 ; P=0.009)$ was also influenced by the feeding intervals to which the predators were submitted, the values obtained with excessive prey and feeding every 2 or 4 days being superior to those obtained when the prey was supplied every 16 days (Table 1 ). However, there was no impact of feeding interval on the oviposition period $(\mathrm{F}=1.68 ; \mathrm{df}=5$, $34 ; P=0.84$ ) (Table 1).

Predators fed an excess of prey, daily or every 2, 4 or 8 days deposited larger clutches (Table 1) and more frequently at the beginning of their lives. However, the decline in egg production started earlier in predators fed an excess of prey and daily; and later in those fed every 2 or 4 days. The clutches and the eggs were better distributed by females of $P$. nigrispinus in the feeding interval of 2 days, whereas in the intervals of 8 or 16 days there was a small production of eggs and clutch.

Exp. 2 (small prey) When the predators were fed with small prey, longevity was not influenced by the feeding interval $(\mathrm{F}=1.67 ; \mathrm{df}=5,42 ; P=0.16)$ (Table 2). For all the feeding 

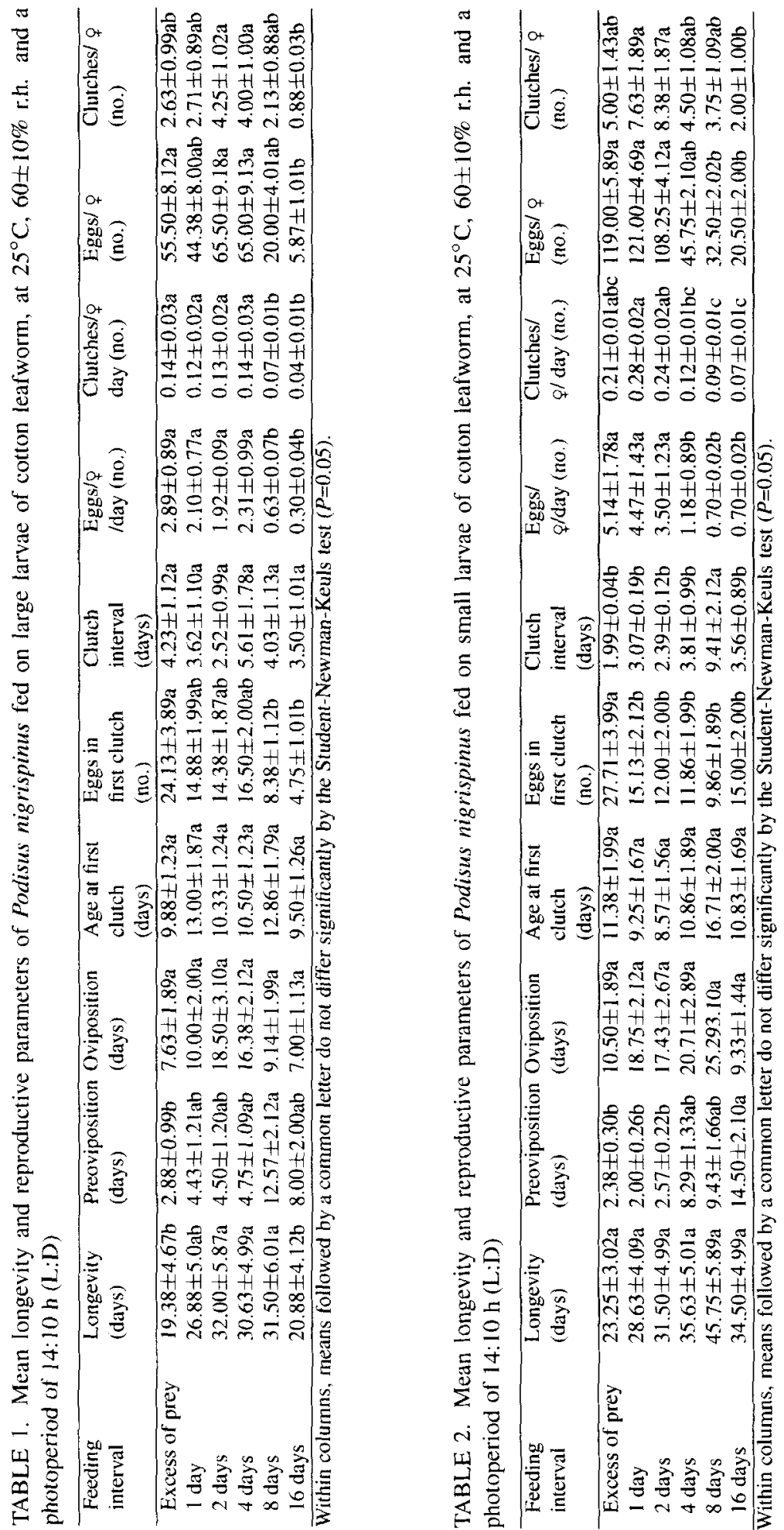
intervals there was at least one individual that lived longer than 40 days; two insects fed every 4 or 8 days lived longer than 60 days, and in the 8 -day feeding interval there was one individual that lived for 99 days.

The preoviposition period of $P$. nigrispinus was affected by feeding interval $(\mathrm{F}=3.10$; $\mathrm{df}=5,37 ; P=0.005$ ), the values being superior in insects fed every 16 days in relation to those fed an excess of prey, daily or every 2 days (Table 2). The number of eggs in the first clutch was also affected by the feeding regimes to which the predators were submitted $(\mathrm{F}=3.65 ; \mathrm{df}=5,36 ; P=0.004)$ ), with the insects that were fed an excess of prey showing a superior value when compared with those submitted to the other alimentary regimes (Table $2)$. The clutch interval $(\mathrm{F}=3.76 ; \mathrm{df}=5,37 ; P=0.005)$, number of eggs per female per day $(\mathrm{F}=8.81 ; \mathrm{df}=5,42 ; P=0.0001)$ and number of clutches per female per day $(\mathrm{F}=5.63 ; \mathrm{df}=5$, $42 ; P=0.003$ ) were also influenced by the feeding interval. The clutch interval was longer in the predators fed every 8 days (Table 2). The number of eggs per female per day was greater in those predators fed an excess of prey, daily or every 2 days, while the number of clutches per female per day was greater in the insects fed daily (Table 2). The different feeding intervals still affected the number of eggs per female ( $\mathrm{F}=4.66 ; \mathrm{df}=5,42 ; P=0.004)$ and of clutches per female $(\mathrm{F}=3.27 ; \mathrm{df}=5,42 ; P=0.005)$, and in those predators fed an excess of prey, daily or every 2 days, the number of eggs per female was greater than those fed every 8 or 16 days; while the number of clutches per female was greater than in the predators fed daily or every 2 days in relation to those fed every 16 days (Table 2 ). However, the oviposition period $(\mathrm{F}=1.43 ; \mathrm{df}=5,34 ; P=0.24)$ and the age of the first clutch of $P$. nigrispinus $(\mathrm{F}=1.64 ; \mathrm{df}=5,37 ; P=0.18)$ were not influenced by the feeding interval to which the predators were subjected (Table 2).

Exp. 3 (no prey) The mean longevity of individuals that received only water was $21.38 \pm 2.71$ days, significantly superior to that of those that did not receive food $(12.26 \pm 0.65$ days) $(\mathrm{F}=10.74 ; \mathrm{df}=1,30 ; P=0.0001)$. The females of the predator that did not receive food oviposited until the 9 th day of age, and those that were fed on water oviposited until the 14th day. After these periods mortality was accentuated in both treatments. However, when the predators did not receive food all the insects died within 17 days, whereas in those that fed only on water, the last individual died after 38 days.

\section{DISCUSSION}

The results obtained in our research on longevity in treatments without prey are similar to those obtained by Wiedenmann and O'Neil (34), De Clercq and Degheele (8), and Legaspi and O'Neil (17) with other species of Podisus; however, unlike the results in our research, none of those workers observed the deposition of clutches. This behavior was found in our study, probably because in the period of 5 days between the eclosion of adults and the beginning of the experiment the predators were fed, thereby obtaining energy for reproduction. Molina-Rugama et al. (22) reported that in periods of prey scarcity, females of $P$. nigrispinus reduce their rate of clutch deposition to benefit the longevity, increasing their survival chances. The influence of feeding interval on the longevity of predators fed on small prey is similar to the data obtained by Wiedenmann and O'Neil (34) for $P$. maculiventris. Mukerji and LeRoux (24) reported increased longevity for both females and males of $P$. maculiventris at low food supplies. The impact of different feeding intervals on longevity was also noted by De Clercq and Degheele (8) for Podisus sagitta, Legaspi 
and O'Neil (17) for mated females of $P$. maculiventris, Molina-Rugama et al. (23) for $P$. rostralis, and by Molina-Rugama et al. (22) for P. nigrispinus.

The length of the preoviposition period recorded in our study was similar to that observed by Wiedenmann and O'Neil (34) when they fed predators on small prey and by De Clercq and Degheele (8) when they fed predators on prey of two different sizes.

Results similar to those obtained in our study on the impact of different feeding intervals on reproductive variables of $P$. nigrispinus were reported by other researchers for other species of stinkbug predators. The clutch interval, the number of eggs per female per day, the number of clutches per female per day, and the number of eggs and clutches per female were similar to those obtained, respectively, by De Clercq and Degheele (8), Wiedenmann and O'Neil (34), Legaspi and O'Neil (17), and De Clercq and Degheele (8).

The results obtained in our study suggest that feeding intervals affect the longevity and reproduction of $P$. nigrispinus. With the increase of the feeding interval, the predators reduced the frequency and size of their clutches. This behavior indicates that $P$. nigrispinus is adapted to the condition of food scarcity in the environment, using the available energy for survival and suppressing reproduction (trade-off), as was observed by Wiedenmann and O'Neil (34), De Clercq and Degheele (8), Legaspi and O'Neil (17), Crumb et al. (5) and Molina-Rugama et al. $(22,23)$ with other pentatomid predators.

Egg predation was observed in females fed at intervals of over 2 days, but the frequency was highest in those predators fed on small prey. This tendency was also observed by Tostowaryk (33) and De Clercq and Degheele (8) in other species of Podisus. This behavior may be considered an additional adaptation of the predators, which increases their chances of survival in periods of prey scarcity in the environment.

One of the main obstacles found by the predators to successful colonization of agroecosystems is obtaining enough food to supply their energy needs, requiring them to adapt to situations of food scarcity, which is doubtless a common situation in nature. The results of our research indicate that $P$. nigrispinus is adapted to this situation, since its reproductive capacity decreased with the increase in feeding interval, evidence that the energy obtained from the prey, when scarce, is used initially to maintain survival, until sufficient food is available to supply energy for the costly reproductive process. Previous studies showed that nymphs of $P$. nigrispinus are capable of developing and surviving to the adult stage under conditions of food scarcity (29).

Based on our findings, we believe that it is important to study the effects of food scarcity in this predator under field conditions to confirm or not our laboratory results, although this kind of study is difficult to conduct. Studies of this nature would allow us to understand certain factors, such as predation, parasitism, competition, and climatic conditions that occur only in natural conditions, influencing the responses of this predator to cotton leafworm populations.

\section{ACKNOWLEDGMENTS}

The authors thank the Brazilian agencies Conselho Nacional de Desenvolvimento Científico e Tecnológico $(\mathrm{CNPq})$ and Fundação de Amparo à Pesquisa do Estado de Minas Gerais (FAPEMIG) for funding. We also express our appreciation to the three anonymous referees for their reviews of our manuscript.

\section{REFERENCES}

1. Andrewartha, H.G. and Birch, L.C. (1954) The Distribution and Abundance of Animals. University of Chicago Press, Chicago, IL, USA. 
2. Beddington, J.R., Hassell, M.P. and Lawton, J.H. (1976) The components of arthropod predation. II. The predator rate of increase. J. Anim. Ecol. 45:165-186.

3. Begon, M., Harper, J.L. and Townsend, C.R. (1990) Ecology, Individuals, Populations and Communities. Sinauer, Sunderland, MA, USA.

4. Conley, M.R. (1985) Predation versus resource limitation in survival of adult burrowing wolf spiders (Araneae: Lycosidae). Oecologia 67:71-75.

5. Crumb. D.A., Weiser, L.A. and Stamp, N.E. (1998) Effects of prey scarcity and plant material as a dietary supplement on an insect predator. Oikos 81:549-557.

6. Dean, J.M. (1981) The relationship between lifespan and reproduction in the grasshopper Melanoplus. Oecologia 48:385-388.

7. De Clercq, P. (2000) Predaceous stinkbugs (Pentatomidae: Asopinae). in: Schaefer, C.W. and Panizzi, A.R. [Eds.] Heteroptera of Economic Importance. Cambridge University Press, Cambridge, UK. pp. 737-789.

8. De Clercq, P. and Degheele, D. (1992) Influence of feeding interval on reproduction and longevity of Podisus sagitta (Het.: Pentatomidae). Entomophaga 37:583-590.

9. Fox, L.R. (1975) Some demographic consequences of food shortage for the predator Notonecta hoffmanni. Ecology 56:868-880

10. Giesel, J.T. and Zettler, E.E. (1980) Genetic correlations of life historical parameters and certain fitness indices in Drosophila melanogaster $m, \mathrm{r}_{s}$, diet breadth. Oecologia 47:299-302.

11. Gutierrez, A.P., Baumgaertner, J.U, and Hagen, K.S. (1981) A conceptual model for growth, development and reproduction in the ladybird beetle, Hippodamia convergens (Coleoptera: Coccinellidae). Can. Entomol. 113:21-33.

12. Hassell, M.P. (1978) The dynamics of arthropod predator-prey systems. Princeton University Press, Princeton, NJ, USA.

13. Inoue, H. (1988) Food availability and reproductive performance in the predator Agriosphodrus dohrni Signoret (Hemiptera: Reduviidae): is its population food-limited in the field? Res. Popul. Ecol. 30:95-105.

14. Juliano, S.A. (1986) Food limitation of reproduction and survival for populations of Brachinus (Coleoptera: Carabidae). Ecology 67:1036-1045.

15. Kaitala, A. (1987) Dynamic life-history strategy of the waterstrider Gerris thoracicus as an adaptation to food and habitat variation. Oikos 48:125-131.

16. Karandinos, M.G. and Axtell, R.C. (1972) Population density effects on fecundity of Hippelates pusio Loew (Diptera: Chloropidae). Oecologia 9:341-348.

17. Legaspi, J.C. and O'Neil, R.J. (1993) Life history of Podisus maculiventris given low numbers of Epilachna varivestis as prey. Environ. Entomol. 22:1192-1200.

18. Lemos, W.P., Ramalho, F.S., Serrão, J.E. and Zanuncio, J.C. (2005) Morphology of female reproductive tract of the predator Podisus nigrispinus (Dallas) (Heteroptera: Pentatomidae) fed on different diets. Braz. Arch. Biol. Technol. 48:129-138.

19. Lenski, R.E. (1982) Effects of forest cutting on two Carabus species: evidence for competition for food. Ecology 63:1211-1217.

20. Mertz, D.B. (1975) Senescent decline in flour beetle strains selected for early adult fitness. Physiol. Zool. 48:1-23.

21. Miyashita, K. (1968) Growth and development of Lycosa T-insignita Boes. et Str. (Araneae: Lycosidae) under different feeding conditions. Appl. Entomol. Zool. 3:81-88.

22. Molina-Rugama, A.J., Zanuncio, J.C., Pratissoli, D. and Cruz, I. (1998) Efeito do intervalo de alimentação na reprodução e na longevidade do predador Podisus nigrispinus (Dallas) (Heteroptera: Pentatomidae). An. Soc. Entomol. Bras. 27:77-84.

23. Molina-Rugama, A.J., Zanuncio, J.C., Zanuncio, T.V. and Oliveira, M.L.R. (1998) Reproductive strategy of Podisus rostralis (Stål) (Heteroptera: Pentatomidae) females under different feeding intervals. Biocontrol Sci. Technol. 8:583-588.

24. Mukerji, M.K. and Leroux, E.J. (1969) The effect of predator age on the functional response of Podisus maculiventris to the prey size of Galleria mellonella. Can. Entomol. 101:314-327.

25. Pearson, D.L. and Knisley, C.B. (1985) Evidence for food as a limiting resource in the life cycle of tiger beetles (Coleoptera: Cicindelidae). Oikos : 161 .

26. Quiring, D.T. and Mcneil, J.N. (1984) Influence of intraspecific larval competition and mating on the longevity and reproductive performance of females of the leaf miner Agromyza frontella (Rondani) (Diptera: Agromyzidae). Can. J. Zool. 62:2197-2200.

27. Ricklefs, R.E. (1990) Ecology. Chiron, Portland, OR, USA.

28. Rowe, L. and Scudder, G.G.E. (1990) Reproductive rate and longevity in the waterstrider Gerris buenoi. Can. J. Zool. 68:399-402. 
29. Santos, T.M., Silva, E.N. and Ramalho, F.S. (1995) Desenvolvimento ninfal de Podisus connexivus Bergroth (Hemiptera: Pentatomidae) alimentado com curuquerê-do-algodoeiro. Pesqui. Agropecu. Bras. 30:163-167.

30. SAS Institute (2004) /STAT User's Guide. Cary, NC, USA.

31. Sota. T. (1984) Long adult life span and polyphagy of a carabid beetle Leptocarabus kumagaii in relation to reproduction and survival. Res. Popul. Ecol. :-400.

32. Tallamy, D.W. and Denno, R.F. (1981) Alternative life history patterns in risky environments: an example from lacebugs. in: Denno, R.F. and Dingle, H. [Eds.] Insect Life History Patterns, Habitat and Geographic Variation. Springer, New York, NY. pp.129-147.

33. Tostowaryk, W. (1971) Life history and behaviour of Podisus modestus (Hemiptera: Pentatomidae) in Boreal forest in Quebec. Can. Entomol. 103:662-674.

34. Wiedenmann, R.N. and O'Neil, R.J. (1990) Effects of low rates of predation on selected life-history characteristics of Podisus maculiventris (Say) (Heteroptera: Pentatomidae). Can. Entomol. 122:271-283.

35. Wise, D.H. (1975) Food limitation of the spider Linyphia marginata: field studies. Ecology 56:637-646.

36. Wise, D.H. (1981) Intra and interspecific effects of density manipulations upon females of two orb-weaving spiders (Araneae: Araneidae). Oecologia 48:252-256. 